line 3 in 8 cases, the reasons for withdrawal were: IE - 6 (75\%), AR - 1 (12.5\%), AdmR - 1 (12.5\%). As a 4-line drug, ADA was prescribed in 4 cases and was canceled in all cases due to IE. On line 5, ADA was assigned 1 time and was discontinuation due to IE.

Golimumab (GLM). He was appointed as the first line in 5 cases. The reasons for withdrawal were: IE - 1 case (20\%), AdmR - 4 appointments (80\%). As a 2-line drug, GLM was prescribed once and was canceled due to AdmR. The drug was not prescribed for the 3rd and 4th lines. As a 5-line therapy, it was prescribed once and was canceled due to IE.

When assessing the frequency of drug withdrawal due to IE or AR, no significant differences were found between the lines of therapy. Discontinuation rates were also not statistically different in the study groups.

Conclusion: The most common reason for the withdrawal of TNF- $\alpha$ in patients with RRA is IE. With an increase in the lines of TNF- $\alpha$ therapy, remission as a reason for withdrawal was not identified. As a result of the increase in the number of sequentially prescribed bDMARDs, the frequency of discontinuation of TNF- $\alpha$ in connection with IE did not decrease. A significant reason for cancellation is $A d m R$, to which we attributed the absence of the drug in the pharmacy network, financial reasons limiting the continuation o

Disclosure of Interests: None declared

DOI: 10.1136/annrheumdis-2021-eular.2347

\section{AB0226 EVALUATION OF RITUXIMAB EFFICACY WITH VARIOUS COMPOSITE MEASURES OF INFLAMMATORY ACTIVITY IN PATIENTS WITH RHEUMATOID ARTHRITIS}

Y. Olyunin ${ }^{1}$, D. Kusevich ${ }^{2}$, E. Nasonov ${ }^{3,4}$. ${ }^{1}$ V.A. Nasonova Research Institute of Rheumatology, Laboratory of Early Arthritis, Moscow, Russian Federation; ${ }^{2}$ V.A. Nasonova Research Institute of Rheumatology, Laboratory of Osteoarthritis, Moscow, Russian Federation; ${ }^{3}$ V.A. Nasonova Research Institute of Rheumatology, Scientific Supervisor, Moscow, Russian Federation; ${ }^{4}$ I.M. Sechenov First Moscow State Medical University, Ministry of Health of Russia (Sechenov University), Department of Therapy and Occupational Diseases, Moscow, Russian Federation

Background: Disease modifying anti-rheumatic drugs (DMARD) can provide an unbalanced effect on individual components of the inflammatory process, which in some cases leads to an insufficiently correct assessment of the patient's status when using composite activity indices [1]

Objectives: To compare the results of the rituximab (RTX) efficacy assessment in patients with rheumatoid arthritis (RA) using different composite indices of disease activity.

Methods: Patients with active RA observed in 23 medical centers of the Russian Federation were included. They were randomized into 2 groups in a 2:1 ratio. In the main group methotrexate (MTX) was prescribed at $15 \mathrm{mg}$ per week and RTX infusions $600 \mathrm{mg}$ on days 1 and 15. Patients in the control group received MTX $15 \mathrm{mg}$ per week and placebo on days 1 and 15 . If after 15 weeks $20 \%$ reduction of tender joint count (TJC) and swollen joint count (SJC) was not achieved, another DMARD was prescribed.

Results: 159 RA patients (131 women and 18 men) were included. The mean age of patients was $51.4 \pm 11.8$ years, the median duration of $\mathrm{RA}-2.8[0.6 ; 5.8]$ years. At baseline DAS28, SDAI and CDAl in all cases assessed disease activity as high. 6 months after RTX administration DAS28 showed remission in $9 \%$, low, moderate and high activity activity in $7 \%, 47 \%$ and $37 \%$ of cases, SDAI - in $7 \%, 12 \%, 34 \%$ and $47 \%, \mathrm{CDAl}-$ in $7 \%, 11 \%, 30 \%$ and $52 \%$, respectively. In the control group remission, low, moderate and high activity by DAS28 were revealed in $2 \%, 2 \%, 38 \%$ and $58 \%$, by SDAI - in $2 \%, 4 \%, 35 \%, 59 \%$, by CDAI - in $2 \%$, $6 \%, 29 \%, 63 \%$ of patients respectively. After 6 months, in patients achieved the treatment target (remission or low activity) according to DAS28, SJC in 12 cases was 0 , in $3-1$ and in $1-2$. TJC was 0 in 9 cases and in 7 patients ranged from 1 to 14 . The level of C-reactive protein (CRP) in 14 cases was within the normal range and in 2 - increased. Erythrocyte sedimentation rate (ESR) was normal in all cases. SDAI after 6 months showed the target activity in 18 patients treated with RTX. In 12 of them the SJC was 0 , in $4-1$ and in $2-2$. In 9 cases TJC was 0 , in the rest patients it varied from 2 to 5 . The level of CRP was normal in 15 patients, ESR - in all patients. CDAl met the target activity in 17 patients. In 12 of them, SJC was 0 , in $3-1$, in $2-2$. The level of CRP was normal in 14, ESR - in all patients.

Conclusion: Assessment of RTX efficacy with DAS28, SDAI, and CDAI in RA provided comparable number of patients who achieved remission or low disease activity 6 months after administration of the drug. The groups of patients who reached this target level of activity by DAS28, SDAI, and CDAI did not have significant differences in the values of main measures characterizing residual inflammatory activity, including SJC, TJC, ESR, and CRP.

REFERENCES:

[1] Bastida C, Soy D, Ruiz-Esquide V, Sanmartí R, et al. Br J Clin Pharmacol. 2019 Aug;85(8):1710-1718.
Disclosure of Interests: None declared

DOI: 10.1136/annrheumdis-2021-eular.2354

\begin{tabular}{l|l}
\hline AB0227 & SAFETY AND EFFECTIVENESS OF ADALIMUMAB \\
REFERENCE PRODUCT AND BIOSIMILAR IN \\
PATIENTS WITH INFLAMMATORY ARTHROPATHIES
\end{tabular}

W. G. Rojas Zuleta ${ }^{1}$, O. J. Felipe Díaz ${ }^{1}$, C. Orozco Gonzalez², J. Barbosa Camacho $^{2}$, C. L. Giraldo Herrera ${ }^{1}$, J. G. Ballesteros ${ }^{1}$, J. H. Donado Gómez ${ }^{2}$, N. Duque Zapata ${ }^{2}$ on behalf of Medicarte Research Group. ${ }^{1}$ Medicarte SAS, Rheumatology, Medellin, Colombia; ${ }^{2}$ Medicarte SAS, Research, Medellin, Colombia

Background: Biological therapy revolutionized the treatment and prognosis of inflammatory arthropathies; however, its high cost has an economic impact on health system and limits its access. Biosimilars are products with similar molecular structure, equivalent efficacy, and comparable safety and immunogenicity, which arise as a necessity to reduce costs. Although, their long-term safety is still to be confirmed ${ }^{1}$

Objectives: Our aim is to compare the safety and effectiveness between adalimumab reference product and biosimilar in patients with inflammatory arthropathies.

Methods: Cohort study of 92 patients with ankylosing spondylitis (AS), rheumatoid arthritis (RA) and psoriatic arthritis (PsA) in a specialized multicenter health institution in Colombia. Ratio of incidence rates (IR) for Adverse Drug Reactions (ADR and therapeutic failure (TF) is estimated among patients exposed to reference product and biosimilar. 95\% confidence interval $(\mathrm{Cl})$ for the ratio is also calculated. ADR and TF Incidences in both groups were calculated using the Kaplan Meier curve. Results: Between October 2019 and October of 2020, 92 patients started adalimumab, 64\% $(n=59)$ reference product and 36\% $(n=33)$ biosimilar (18 naive and 15 switch). $41.3 \%$ of patients had a diagnosis of RA, $35 \%$ AS and $24 \%$ PAs. Additionally, $62 \%$ were women, with median age of 53 years (Interquartile Range (IQR): 41-62); disease evolution time of 9 years (IQR: $5-20)$; and treatment time of 0.8 years (IQR: $0.4-1.04$ ). No statistically significant differences were found according to the drug between diagnosis, evolution time, or disease activity. Of all patients 21 presented ADR; 11 events with reference product (IR 0.18 per 100 person-years), and 10 with biosimilar (IR 0.30 per 100 person-years), IR ratio of $0.61(95 \% \mathrm{Cl} 0.26-1.44$; $\mathrm{p}$-value $=0.36)$. From ADR reactions, $35 \%$ were infec tions, $13 \%$ skin disorders and $7.4 \%$ hepatobiliary disorders; all were classified as non-serious ADR. 5 TF events were presented, 3 with reference product (IR 0.05 per 100 person-years) and 2 with biosimilar (IR 0.06 per 100 person-years); IR ratio of $0.83(95 \% \mathrm{Cl} 0.09-10.04 ; \mathrm{p}$ value $=1.00)$. There was no statistically significant between reference product and biosimilar in time of ADR presentation (Log Rank Test $0.74 ; p=0.39$ ) or on TF (Log Rank Test $0.55 ; p=0.45$ ).

Conclusion: Results shown that analyzed biosimilar is a safe product with a similar rate of ADR and without differences in effectiveness evaluated by TF although $95 \% \mathrm{Cls}$ are imprecise. This suggests that use of biosimilars in a reallife setting could be safe and with similar effectiveness, which is correlated with other studies carried out in RA and is an appropriate measure to reduce treatment costs in patients with inflammatory arthropathy.

\section{REFERENCES:}

[1]Cohen, S. B. et al. Long-term safety, efficacy, and immunogenicity of adalimumab biosimilar BI 695501 and adalimumab reference product in patients with moderately-to-severely active rheumatoid arthritis: results from a phase $3 \mathrm{~b}$ extension study (VOLTAIRE-RAext). Expert Opin. Biol.Ther. 19, 1097-1105 (2019).

Acknowledgements: To Medicarte for the support

Disclosure of Interests: Wilmer Gerardo Rojas Zuleta Speakers bureau: Pfizer, Jannsen Cilag, Novartis, Bristol Myers Squibb, Biopass, Amgen, Paid instruc tor for: Pfizer, Jannsen Cilag, Novartis, Bristol Myers Squibb, Biopass, Amgen, Oscar Jair Felipe Díaz Speakers bureau: Amgen, Jannsen Cilag, Bristol Myers Squibb, Novartis, Ely-Lilly, Catalina Orozco Gonzalez: None declared, Jhyld Barbosa Camacho: None declared, Claudia Lucía Giraldo Herrera Speakers bureau: Jannsen Cilag, Bristol Myers Squib, Amgen, Pfizer, Novartis, Roche, Paid instructor for: Jannsen Cilag, Bristol Myers Squib, Amgen, Pfizer, Novartis, Roche, Jesús G Ballesteros Speakers bureau: Bristol Myers, Pfizar, Amgen, Jannsen Cilag, Paid instructor for: Bristol Myers, Pfizar, Amgen, Jannsen Cilag, Jorge Hernando Donado Gómez: None declared, Natalia Duque Zapata: None declared DOI: 10.1136/annrheumdis-2021-eular.2592

\begin{tabular}{|l|l|}
\hline AB0228 & LONG-TERM EFFECTIVENESS, DRUG SURVIVAL OF \\
BIOLOGIC THERAPIES IN PATIENTS WITH ACTIVE \\
RHEUMATOID ARTHRITIS AND SPONDYLOARTHRITIS \\
AND PREDICTIVE FACTORS OF DRUG \\
DISCONTINUATION DUE TO DISEASE REMISSION
\end{tabular}

K. Preedeekanit ${ }^{1}$, A. Koolvisoot ${ }^{2}{ }^{1}$ Faculty of Medicine Siriraj Hospital, Mahidol University, Department of Medicine, Bangkok, Thailand; ${ }^{2}$ Faculty of Medicine 
Table 1. Effectiveness, Drug Survival and Causes of Biologic Discontinuation in RA and SpA

\begin{tabular}{|c|c|c|c|c|c|c|c|c|c|}
\hline \multicolumn{10}{|l|}{ RA \% (87 cases) } \\
\hline \multirow[t]{2}{*}{ Biologics } & \multirow[t]{2}{*}{ Total \% (N) } & \multirow{2}{*}{$\begin{array}{c}\text { 5-year Remission } \\
\text { rate } \%\end{array}$} & \multirow{2}{*}{$\begin{array}{c}5 \text {-year Drug } \\
\text { survival rate \% }\end{array}$} & \multicolumn{6}{|c|}{ Discontinuation \% (N 53 cases) } \\
\hline & & & & $\begin{array}{l}\text { Total \% } \\
\text { (53) }\end{array}$ & Remission & $\begin{array}{l}\text { Inadequate } \\
\text { response }\end{array}$ & Side effect & Non-adherence/ Refer & Death \\
\hline Etanercept & $49.4(43)$ & 23.9 & 33.6 & $50.9(27)$ & $14.8(4)$ & $44.4(12)$ & $22.2(6)$ & $11.1(3)$ & $7.4(2)^{*}$ \\
\hline Infliximab & $5.7(5)$ & & 36 & $5.7(3)$ & $0(0)$ & $33.3(1)$ & $33.3(1)$ & $33.3(1)$ & (0) \\
\hline Rituximab & $44.8(39)$ & & 40.7 & $43.4(23)$ & $56.5(13)$ & $17.4(4)$ & $4.3(1)$ & 13.0(3) & $8.7(2)$ \\
\hline \multicolumn{10}{|l|}{ SpA \%(49 cases) } \\
\hline \multirow[t]{2}{*}{ Biologics } & \multirow[t]{2}{*}{ Total \% (N) } & \multirow{2}{*}{$\begin{array}{c}5 \text {-year Remission } \\
\text { rate } \%\end{array}$} & \multirow{2}{*}{ Drug survival rate } & \multicolumn{6}{|c|}{ Discontinuation \% (N 23 cases) } \\
\hline & & & & Total \% (23) & Remission & $\begin{array}{r}\text { Inadequate } \\
\text { response }\end{array}$ & Side effect & Non-adherence/ Refer & Death \\
\hline Etanercept & $83.6(41)$ & 66.7 & 50.3 & $78.3(18)$ & $22.2(4)$ & $22.2(4)$ & $33.3(6)$ & $22.2(4)$ & $0(0)$ \\
\hline Infliximab & $16.4(8)$ & & 0 & $21.7(5)$ & $20(1)$ & $20(1)$ & $40(2)$ & $20(1)$ & $0(0)$ \\
\hline
\end{tabular}

${ }^{*}$ Cause of death: sudden cardiac death (1), intraabdominal infection (1)

Cause of death: pneumonia (1), Lung cancer (1)

\section{Siriraj Hospital, Mahidol University, Division of Rheumatology, Department of} Medicine, Bangkok, Thailand

Background: Rheumatoid arthritis (RA) and spondyloarthropathies (SpA) are chronic rheumatic diseases that can progress to disability if left uncontrolled. Biologic therapies can induce remission in patients with inadequate response or intolerance to conventional synthetic disease-modifying antirheumatic drugs (csDMARDs). Due to the safety and economic concern, updated treatment recommendations now consider biologics discontinuation in patients with persistent remission. However, available data are still limited.

Objectives: To evaluate the biologics effectivenss, drug survival, rate of discontinuation in real-life practice and to identify predictors of biologics discontinuation due to remission in RA and SpA.

Methods: A total of 87 patients with RA and 49 patients with SpA, starting biologics between January 2005 and October 2020, were recruited from the Rheumatic Disease Prior Authorization (RDPA) registry of Siriraj hospital. Baseline data were recorded. Time-dependent rates in achieving remission were calculated. Cumulative probability of biologics discontinuation and predictive factors of drug discontinuation due to remission were analyzed.

Results: The biologics used in RA patients were Etanercept (49.4\%), Rituximab $(44.8 \%)$, and Infliximab (5.7\%). The 1- and 5- year remission rates were $8.5 \%$ and $23.9 \%$, respectively. Drug survival rates were $33.6 \%$ for Etanercept, $40.7 \%$ for Rituximab, and $36 \%$ for Infliximab at five years. The main reasons for drug discontinuation were disease remission $(32.1 \%)$, inadequate response $(32.1 \%)$, and side effects (15.1\%). Rituximab had the highest discontinuation rate due to remission $(56.4 \%)$. There was no predictive factor for biologics discontinuation due to remission.

SpA patients were treated with Etanercept (83.6\%) and Infliximab (16.4\%). The 1 - and 5 - year remission rates were $67.4 \%$ and $66.7 \%$, respectively. Drug survival rates were $50.3 \%$ for Etanercept and $0 \%$ for Infliximab at five years. Biologics withdrawal due to side effects occurred in $16 \%$, inadequate response in $10 \%$, and disease remission in $10 \%$ of patients. The predictive factor for biologics discontinuation due to remission was disease duration $<5$ years (Hazard ratio 6.92, $95 \% \mathrm{Cl} 1.10,43.29$ )

Conclusion: Biologic therapies are effective in patients with active RA and SpA despite csDMARDs treatment. The highest drug survival rates are Rituximab in RA and Etanercept in SpA. Infliximab has the shortest drug retention rate in SpA. Drug discontinuation due to remission is more successful in RA patients, particularly in the Rituximab group. The best predictor for biologics discontinuation due to remission in SpA is the disease duration of fewer than five years.

Disclosure of Interests: None declared

DOI: 10.1136/annrheumdis-2021-eular.2776

\begin{tabular}{|l|l}
\hline AB0229 & A NATIONAL, MULTICENTER, SECONDARY DATA USE \\
STUDY EVALUATING EFFICACY AND RETENTION \\
OF FIRST-LINE BIOLOGIC TREATMENT WITH \\
TOCILIZUMAB IN PATIENTS WITH RHEUMATOID \\
ARTHRITIS IN REAL-LIFE SETTING FROM TURKBIO \\
REGISTRY
\end{tabular}

A. Yazici', Ö. Özdemir Işık' ${ }^{1}$, E. Dalkılıç², S. S. Koca ${ }^{3}$, Y. Pehlivan² ${ }^{2}$ S. Şenel ${ }^{4}$, N. Inanc ${ }^{5}$, S. Akar ${ }^{6}$, S. Yılmaz ${ }^{7}$, Ö. Soysal Gündüz ${ }^{8}$, A. Cefle ${ }^{1}$, F. Onen ${ }^{9}$. ${ }^{1}$ Kocaeli University Faculty of Medicine, Department of Internal Medicine Division of Rheumatology, Kocaeli, Turkey; ${ }^{2}$ Uludağ University Faculty of Medicine, Department of Internal Medicine Division of Rheumatology, Bursa, Turkey; ${ }^{3}$ FIrat University Faculty of Medicine, Department of Internal Medicine Division of Rheumatology, Elazı $\breve{g}$, Turkey; ${ }^{4}$ Erciyes University Faculty of Medicine, Department of Internal Medicine Division of Rheumatology, Kayseri, Turkey; ${ }^{5}$ Marmara University Faculty of Medicine, Department of Internal Medicine Division of Rheumatology, İstanbul, Turkey; ${ }^{6}$ Katip Çelebi University Faculty of Medicine, Department of Internal Medicine Division of Rheumatology, İzmir, Turkey; ' Selçuk University Faculty of Medicine, Department of Internal Medicine Division of Rheumatology, Konya, Turkey; ${ }^{8}$ Celal Bayar University Faculty of Medicine, Department of Internal Medicine Division of Rheumatology, Manisa, Turkey; ${ }^{9}$ Dokuz Eylül University Faculty of Medicine, Department of Internal Medicine Division of Rheumatology, İzmir, Turkey

Background: Tocilizumab (TCZ) is a human anti-interleukin (IL)-6 receptor antibody approved in Turkey for the treatment of rheumatoid arthritis (RA).

Objectives: In this study our purpose was to describe the disease activity, quality of life (QoL), and retention rate in RA patients who were prescribed TCZ as first-line biologic treatment in a real-world setting.

Methods: Anonymized patient registry of TURKBIO was used based in a national, multicenter, and retrospective context. We conducted a search in the registry between years 2013 and 2020 and included adult RA patients who were prescribed with $T C Z$ as their first-line biologic treatment with a post-TCZ follow-up of at least 6 months. CDAI, DAS28-(ESR), and HAQ-DI scores in 6, 12 , and 24 months were obtained. Pairwise comparison was carried out for survey scores across baseline and timepoints. Subgroup analysis for route of TCZ administration was performed. EULAR response criteria were used for response evaluation. Retention of TCZ was evaluated by Kaplan-Meier analysis.

Results: Overall, 130 patients with a mean RA duration of 14 years were included in the study. $87.7 \%$ of the patients were female and mean age was 53 (SD; 15.0). Median duration of follow-up was 18.5 months. Majority $(90.8 \%)$ of patients were given tocilizumab via intravenous route at baseline. Number of patients with ongoing TCZ treatment and follow-up at 6, 12, and 24 months were $121(93 \%), 85(65 \%)$, and $46(35 \%)$, respectively. Remission rates at 6,12 , and 24 months per CDAI $(<2.8)$ and DAS28-(ESR) $(<2.6)$ scores were $61.5 \%, 44.6 \%, 30 \%$, and $54.6 \%, 40.8 \%, 27.7 \%$, respectively. CDAI, DAS28(ESR) and HAQ-DI survey scores significantly improved at 6, 12 and 26 months, respectively $(p<0.001)$ (Table 1$)$ in both IV and SC TCZ subgroups. At 6, 12 and 24 months $74.8 \%, 82.5 \%$ and $86.4 \%$ of patients achieved a EULAR good response respectively. Twenty-three patients (17.6\%) discontinued TCZ at 24 months. Of these, 19 patients discontinued due to unsatisfactory response. Retention rates of TCZ at 6,12 , and 24 months were $93 \%, 84.3 \%$, and $72.2 \%$, respectively (Figure 1).

Conclusion: TCZ as a first-line biologic treatment was found to be clinically effective in this real-world study with a high retention rate. These results are in line with the results gathered from previous TCZ controlled and real-life studies in which TCZ was found clinically safe and effective.

\section{REFERENCES:}

[1] Haraoui B, Casado G, Czirjak L, Taylor A, Dong L, Button P, Luder Y, Caporali R. Tocilizumab Patterns of Use, Effectiveness, and Safety in Patients with Rheumatoid Arthritis: Final Results from a Set of Multi-National Non-Interventional Studies. Rheumatol Ther. 2019 Jun;6(2):231-243.

[2] Favalli EG, Raimondo MG, Becciolini A, Crotti C, Biggioggero M, Caporali $R$. The management of first-line biologic therapy failures in rheumatoid arthritis: Current practice and future perspectives. Autoimmun Rev. 2017 Dec;16(12):1185-1195.

[3] Haraoui B, Jamal S, Ahluwalia V, Fung D, Manchanda T, Khraishi M. RealWorld Tocilizumab Use in Patients with Rheumatoid Arthritis in Canada: 12-Month Results from an Observational, Noninterventional Study. Rheumatol Ther. 2018 Dec; 5(2): 551-565. 